\title{
COM QUANTOS ENUNCIADOS SE PRODUZ O MAU ALUNO?
}

\author{
Sandra Nazaré Dias Bastos ${ }^{1}$ \\ Sílvia Nogueira Chaves ${ }^{2}$
}

\begin{abstract}
RESUMO
Inúmeros atos cotidianos nas escolas são expressões sutis de importantes relações de poder que se encontram naturalizadas pelo tempo e pelos atores desse cenário. Dentro desse contexto, trouxemos para discussão duas situações nas quais o discurso proferido pelo professor funciona como elemento de poder, verdade e subjetivação. Acionamos como ferramenta para nossas problematizações o pensamento de Michel Foucault que aponta para os efeitos produtivos do discurso que se materializa na organização das relações entre indivíduos e instituições, com isso estabelecendo hierarquias e distinções. Instituída por práticas discursivas e não discursivas, a relação estabelecida entre esses dois atores enreda situações de autoridade e submissão nas quais o professor tem a voz da verdade e da sabedoria e aos alunos cabe o papel de acatar e internalizar essa voz como uma prática a ser incorporada como verdadeira não só no universo pedagógico como também na vida social.
\end{abstract}

Palavras-chave: Análise do Discurso. Formação de Professores. Subjetivação.

\begin{abstract}
Numerous daily acts in schools are subtle expressions of important power relations that are naturalized by time and actors in this scenario. Within this context, we have brought to discussion two situations in which the speech delivered by the teacher functions as an element of power, truth and subjectivation. We act as a tool for our problematizations the thought of Michel Foucault, which points to the productive effects of the discourse, that is materialized in the organization of the relations between individuals and institutions establishing hierarchies and distinctions. Instituted by discursive and non-discursive practices the established relationship between these two actors entangles situations of authority and submission in which the teacher has the voice of truth and wisdom and the students the role of accepting and internalizing this voice as a practice to be incorporated as true not only in the pedagogical universe but also in social life.
\end{abstract}

Keywords: Discourse Analysis. Teacher Training. Subjectivation.

\section{INTRODUÇÃO}

Ao escrever esse texto procuramos buscar em nossas memórias situações ou momentos que consideramos determinantes em nosso processo de contínua formação. Revirando o baú de lembranças separamos duas situações que, embora distanciadas no tempo, consideramos complementares para a discussão que pretendemos tratar. Tomamos como ponto de partida a ideia de que a escola, além de espaço pedagógico, é o local onde

\footnotetext{
${ }^{1}$ Doutora em Educação em Ciências e Matemática pela UFPA. Professora Adjunta IV do Instituto de Estudos Costeiros da UFPA, Campus Universitário de Bragança. Grupo de Estudos e Pesquisa em Educação Científica e Ambiental (GEPECA). E-mail: sbastos@ufpa.br

${ }^{2}$ Doutora em Educação pela UNICAMP. Professora Associada IV do Instituto de Educação Matemática e Científica. Grupo de Pesquisa em Cultura e Subjetividade (GEPECS). E-mail: schaves@ufpa.br
} 
importantes interações acontecem. Nas palavras de Gadotti (2007, p. 11) a escola é um espaço de pessoas e relações e não somente um local para estudar, não é somente um espaço físico, mas um local de encontros, conversas e políticas. Nesse espaço, práticas discursivas determinadas por relações de poder, conferem autoridade a alguns e submissão a outros, e se estabelecem a partir de conflitos e afetos desempenhando papel importante como elementos produtores de subjetividade. Assim, a escola se constitui enquanto espaço normalizador através do que Menezes (2008, p.38) chama de cristalização pedagógica da dinâmica de produção das relações de poder. Assim, o espaço escolar articula-se de um lado com a pedagogia da ortopedização ${ }^{3}$ dos indivíduos e de outro com uma pedagogia que produz modos de subjetivação por meio de dispositivos de normalização. É nesse cenário que se mantém em destaque duas figuras, ou melhor, dois atores - professor e aluno - que dividem entre si o papel principal nos enredos vivenciados na escola.

As duas cenas que seguem, serão utilizadas para problematizar relações de poder exercidas por meio de práticas discursivas. A primeira cena aconteceu em uma escola de Educação Básica envolvendo aluna do curso de Licenciatura em Biologia que desenvolvia suas atividades de estágio supervisionado. A segunda cena traz a mesma estagiária agora na condição de professora atuando em um curso de formação de professores de Pedagogia. Em ambos os casos o pano de fundo é o discurso revestido de autoridade proferido por professores e que por ser proferido de um local privilegiado, se torna verdade ao ser incorporado ou aceito por quem o escuta.

\section{CENA 1 - O PEQUENO JOSÉ}

Em uma exposição sobre a importância da merenda escolar, os cartazes estavam dispostos em um grande círculo na área livre da escola em frente à copa. Diante de cada cartaz uma pessoa responsável por explicar aos alunos do Ensino Fundamental uma parte do tema. Chegou a vez da segunda série. Um garoto, o menor da turma, conseguiu chegar na frente de todos. Ficou ali parado na frente do cartaz esperando pela explicação. Quando o restante da turma chegou, ele foi aos poucos sendo empurrado para trás pelos colegas e logo ficou tão atrás que não consegui ver mais nada. Antes que a apresentação terminasse ele correu para o segundo cartaz e mais uma vez ficou esperando a explicação. E novamente toda

\footnotetext{
${ }^{3} \mathrm{O}$ termo ortopedização refere-se ao poder disciplinar da escola, instituição que entre outras funções se propõe a corrigir e evitar as "deformidades" de seus indivíduos. Segundo Foucault o poder disciplinar age sobre os corpos fabricando corpos submissos e exercitados, corpos "dóceis". É dócil um corpo que pode ser submetido, que pode ser utilizado, que pode ser transformado e aperfeiçoado (FOUCAULT, 2009b, p. 118).
} 
a cena se repetiu no terceiro cartaz, no quarto... presenciando a cena, a aprendiz de professora tomou o lugar de sua colega e se posicionou diante do cartaz seguinte. Quando o menino foi mais uma vez empurrado para trás, ela saiu em sua defesa. Pegando-o pelo braço e o posicionando na frente dos demais alunos falou: "Esperem aí, nosso amigo aqui foi o primeiro a chegar, é justo que fique na frente, até mesmo porque ele é o menor, lá atrás não vai conseguir ver nada!" A professora que acompanhava a turma imediatamente falou em alto e bom som: "Não vale a pena perder tempo com ele. Esse menino não quer nada! Ele é burro, e preguiçoso, não aprende!. Ele só vem para a escola para dormir na carteira". Diante disso os outros alunos começaram o coro: "José é preguiçoso! José é dorminhoco!". E o menino que já era pequeno foi ficando cada vez menor.

\section{CENA 2 - PROFESSORES-ALUNOS DO CURSO DE LICENCIATURA EM PEDAGOGIA}

Em uma reoferta ${ }^{4}$ de disciplina para o curso de Pedagogia sob o regime de contrato ${ }^{5}$, a professora viveu uma situação inusitada: acostumada a ser recebida de forma calorosa pelas turmas se deparou com alunos apáticos que pareciam cansados e desestimulados. Como vinham de outros municípios pensou que, como ela, a viagem longa e desconfortável fosse o motivo daquele estado de ânimo. Ela apresentou sua programação, falou sobre os textos e filmes que seriam trabalhados e da avaliação final: a elaboração de um projeto. Os nove alunos permaneciam indiferentes. As aulas seriam ministradas em uma casa cedida pela prefeitura, pois não havia sala de aula disponível para abrigar a aquela turma. Era lá que ela ficaria hospedada e as aulas seriam ministradas em dois turnos com um pequeno intervalo para almoço e descanso. Terminado o primeiro turno de atividades ainda faltava uma aluna. Os outros informaram que a localidade dessa professora era muito distante, não havia condução para aqueles lados e ela precisaria além de caminhar um bocado, esperar por uma carona que a levasse até o ponto de ônibus mais próximo. Ela chegou depois do almoço, cansada, desgrenhada e com cara de faminta. A professora que já havia almoçado sozinha, ofereceu a comida que havia sobrado em sua marmita e nesse momento, aproveitando que

\footnotetext{
${ }^{4}$ Uma reoferta de disciplina ocorre para alunos reprovados ou que por algum motivo não puderam cursá-la no período regular do curso.

${ }^{5}$ As turmas eram assim chamadas por serem ofertadas mediante um convênio firmado entre a Instituição de Ensino Superior, no caso a UFPA com prefeituras para qualificar os professores que atuavam na educação infantil de cada município - nesse caso a clientela atendida era de professores que estavam ali na condição de alunos.
} 
alguns alunos já haviam chegado para o segundo turno de atividades, os chamou para tomar um café e fazer companhia à aluna recém-chegada que a essa altura finalizava seu almoço. Com todos reunidos em volta da mesa, calados e meio sem jeito, ela comentou que não gostava de fazer as refeições sozinha e que poderiam montar um esquema de cada um trazer um pouco de comida para fazerem as refeições juntos. Eles se olhavam e ao mesmo tempo olhavam espantados para a professora. Foi Manoel quem fez a pergunta: "professora a senhora é formada em que?" "Sou formada em Biologia e recentemente concluí o mestrado em Biologia Ambiental”. "Mestrado?!" O misto de pergunta e espanto saiu da boca de pelo menos quatro alunos. "Mestrado sim, por quêe?". "Por que não parece!" "E não parece por quê?" "Por que a senhora está tratando a gente como gente". "E vocês não são gente?".

Ainda meio atordoada com o rumo daquela prosa, e sem saber ao certo o que estava se passando, ouviu de Manoel a seguinte situação: “O professor que veio ministrar a disciplina antes da senhora disse que não era homem de perder tempo. Que estava ali para nos ensinar Biologia e que só aprendia quem era bom. Com mestrado no exterior, era uma pessoa muito capacitada para se ver metida naquele fim de mundo perdendo tempo com quem não tinha condições de aprender. Assim, passada a primeira avaliação ele nos separou (os dez alunos da reoferta) em um canto da sala e disse para toda a turma ouvir. 'Esses aqui tiraram as menores notas da turma. Mas eu já esperava por isso, na verdade, estou surpreso por serem só dez. Como já disse, não vou perder tempo com quem não aprende’. E virando-se para nós, encolhidos no canto da sala, falou: 'Assim, se quiserem ir embora, façam o favor! Mas, se decidirem ficar, já aviso que estão todos reprovados'. Ficamos lá até o final da disciplina. Ele não nos perguntava nada, não pudemos apresentar os trabalhos e ninguém quis fazer equipe com a gente. Ficamos lá só olhando e servindo de chacota na turma... Ninguém intercedeu por nós. E agora vem a senhora com essa história de projeto como avaliação final da disciplina. Se não sabemos nem fazer uma prova que dirá fazer um projeto! Já sabemos que vamos ficar todos reprovados novamente."

\section{SOBRE A ORDEM DO DISCURSO, VERDADE E PODER}

A verdade, como o relâmpago, não nos espera onde temos a paciência de emboscá-la e a habilidade de surpreendê-la, mas que tem instantes propícios, lugares privilegiados, não só para sair da sombra como para realmente se produzir.

Michel Foucault - Microfísica do Poder 
Os discursos estabelecem hierarquias, distinções, produzem efeitos que se materializam na organização das relações entre indivíduos e instituições. Foucault defende a ideia de que o discurso forma sujeitos por ser uma instituição material que traz consigo o poder de reduzir as asperidades pela naturalização daquilo que torna objeto e expressa sua ligação com o desejo e com o poder (FOUCAULT, 2009a).

Nessa perspectiva, o poder não é visto como algo negativo ou repressor. Foucault afirma que o poder é uma rede produtiva que atravessa todo o corpo social e para que se mantenha e seja aceito ele não pesa como uma força que diz não, mas que produz coisas, forma saber e produz discurso. Nas palavras do autor:

Se o poder fosse somente repressivo, se não fizesse outra coisa a não ser dizer não você acredita que seria obedecido? O que faz com que o poder se mantenha e que seja aceito é simplesmente que ele não pesa só como uma força que diz não, mas que de fato ele permeia, produz coisas, induz ao prazer, forma saber, produz discurso. Deve-se considerá-lo como uma rede produtiva que atravessa todo o corpo social muito mais do que uma instância negativa que tem por função reprimir (FOUCAULT, 1979, p. 8).

Assim, o poder é produtor de individualidade e o indivíduo é, portanto, uma produção da relação poder-saber. Nesse contexto, a educação, embora seja um direito, é também o local onde se pode ter acesso a qualquer tipo de discurso. Todo sistema de educação é uma maneira política de manter ou de modificar a apropriação dos discursos, com os saberes e os poderes que eles trazem consigo. Prosseguindo com essa ideia Foucault faz a seguinte afirmaçãopergunta:

\footnotetext{
o que é afinal um sistema de ensino senão uma ritualização da palavra; senão uma qualificação e uma fixação do papeis para os sujeitos que falam; senão a constituição de um grupo doutrinário ao menos difuso; senão uma distribuição e uma apropriação do discurso com seus poderes e seus saberes? (FOUCAULT, 2009a, p. 44-45).
}

$\mathrm{Na}$ escola as relações de poder normalmente ocorrem de forma sutil e passam despercebidas pelos sujeitos por estarem naturalizadas na demarcação dos papeis a serem exercidos por professor e alunos. O contexto das duas cenas mostra uma relação assimétrica de poder na qual aquele que ensina, o professor, exerce autoridade sobre aquele que aprende, o aluno e por este motivo a constituição subjetiva do aluno se dá pelo discurso ditado por quem de direito, o professor. Este por sua vez, põe em cheque a capacidade de aprender e consequentemente de um dia vir a ser "alguém" dos alunos.

Pereira (2000, p. 12) afirma que dentro da escola o professor é o agente que faz funcionar as normas a partir de uma delegação social. Como forma de demonstrar sua autoridade o professor estabelece com seus alunos códigos gestuais e verbais que acabam por demarcar os papéis dentro da sala de aula e o lugar que cada um deve ocupar. Nessa 
concepção cabe ao aluno ficar sentado, atento, preferencialmente calado e pronto para cumprir suas obrigações. O professor tem o poder de determinar as ações dos alunos, e estes legitimam esse poder fortalecendo a imagem do professor como uma figura que tem o direito de exercer a autoridade. A relação estabelecida entre o professor e seus alunos é uma relação construída por ambos e instituída por práticas discursivas e não discursivas ${ }^{6}$ que determinam autoridade e submissão: o professor tem a voz da verdade e da sabedoria e aos alunos cabe o papel de acatar e internalizar essa voz como uma possibilidade a ser desenvolvida ou uma prática a ser incorporada como verdadeira.

A verdade é, portanto, produzida pela materialidade do discurso e inexiste fora do poder. Eizirik (2005, p. 42) traz a concepção de Foucault sobre verdade:

\begin{abstract}
A verdade deve ser entendida como um sistema de procedimentos ordenados para produção, regulação, distribuição, circulação e operação dos discursos. Ela está ligada em uma relação circular com sistemas de poder que a produzem e sustentam e com os efeitos do poder que ela induz e que a expandem.
\end{abstract}

Dentro desse contexto, o autor defende o efeito produtivo da verdade ao afirmar que, se por um lado somos impelidos a dizer sempre a verdade, por outro lado somos igualmente submetidos por ela. Essa submissão está no sentido de que a verdade funciona como uma norma a ser seguida ou obedecida. A verdade é o discurso verdadeiro que decide, veicula e propulsa efeitos de poder. Os discursos verdadeiros apresentam efeitos específicos de poder que são capazes de condenar, classificar, localizar e até mesmo produzir certa maneira de viver (FOUCAULT, 2005, p. 29).

No entanto, a verdade discursiva está ligada às posições ocupadas pelos sujeitos na sociedade. Para ter efeito de verdade o discurso não pode ser proferido por qualquer pessoa. Existe uma ordem que sustenta a validade do discurso e de seus efeitos: quem fala, deve falar de algum lugar. No caso dos professores que ilustram esse artigo, o lugar que ocupam é o lugar da verdade, da certeza, da sabedoria, da profetização dos acontecimentos futuros... Ao dizerem a seus alunos: "Vocês não aprenderão nada", "José não quer nada" são referendados pelos colegas de José que o chamam de preguiçoso e pelos demais alunos da turma de Pedagogia que se negam a formar equipes com os alunos excluídos pelo professor. Esse discurso torna-se então "mais verdadeiro" ao ser recebido pelos sujeitos como regras. Regras

\footnotetext{
${ }^{6}$ A prática discursiva se refere ao conjunto de enunciados que molda nossa maneira de ver o mundo e falar sobre ele. As práticas não discursivas referem-se às condições de possibilidades (sejam elas sociais, econômicas, históricas e políticas) que promovem o aparecimento e a manutenção dos discursos na sociedade, com isso garantindo seu status de verdade.
} 
que demarcam o poder do professor, pois reconhecem seu direito de classificar comportamentos na escola.

O discurso proferido pelo professor naturaliza práticas que associam os sujeitos a determinados espaços que se tornam visíveis quando os alunos de Pedagogia são separados dos demais e quando José fica para trás. O espaço ocupado por esses sujeitos é o lugar do atraso, da incompetência e acima de tudo da inviabilidade. A fala do professor é tomada como o prenúncio da concretização de uma verdade. A verdade que o professor acredita e que o aluno internaliza como sendo também a sua verdade. É o discurso verdadeiro proferido por quem de direito e que por este motivo tem a capacidade de profetizar o futuro e contribuir para sua realização pela adesão dos envolvidos (FOUCAULT, 2009a, p. 15).

É importante destacar que o poder não deve ser visto como algo que, apenas e tão somente, submete ou destrói o indivíduo, mas ao contrário: o fabrica pelo seu efeito de verdade. Dentro desse contexto, também é importante ressaltar que o sujeito é um efeito do poder e não um núcleo elementar no qual o poder é aplicado.

Mas, como funciona esse poder capaz de produzir discursos de verdade dotados de efeitos tão potentes?

Foucault não defende o poder enquanto algo unitário e global. Para ele, o poder deve ser visto como uma prática social, historicamente construída e que, por este motivo, se apresenta em constante transformação. Assim, os poderes são exercidos em níveis variados, em pontos diferentes da rede social, como não estão localizados em nenhum nível específico de sua estrutura funcionando, portanto como dispositivos ${ }^{7}$ a que nada ou ninguém escapa.

Este princípio põe em cheque a concepção tradicional do poder enquanto exercício vertical centralizado na figura do estado ou do soberano, concebido como essência vinculada a uma identidade única. O poder se manifesta enquanto exercício plural e relacional exercido em práticas heterogêneas e sujeitas a transformações, ou seja, “o poder se dá em conjunto com práticas sociais constituídas historicamente que atuam por meio de dispositivos estratégicos que alcançam a todos e dos quais ninguém pode escapar, pois não se encontra uma região da vida social que esteja isenta de seus mecanismos” (DUARTE, 2008, p. 45).

É com base nessa tese foucaultiana que entendemos o sujeito como um efeito. Produto de uma multiplicidade de relações horizontais de saber-poder que o caracterizam como sujeito

\footnotetext{
7 O termo dispositivo demarca um conjunto bastante heterogêneo que correspondem a mecanismos de dominação. Engloba discursos, instituições, organizações arquitetônicas, decisões regulamentares, leis, medidas administrativas, enunciados científicos, proposições filosóficas, morais, filantrópicas. Em suma, o dito e o não dito são os elementos do dispositivo. O dispositivo é a rede que se pode estabelecer entre estes elementos (FOUCAULT, 1979, p.244).
} 
assujeitado e disciplinado e, nesse cenário, a escola é o lugar (ou instituição) que funciona como a dobradiça que articula, de forma íntima e eficiente, o saber com o poder (VEIGANETO, 2008, p. 30). Poder que tem a capacidade de intervir materialmente atingindo a realidade mais concreta dos indivíduos - constituída pelo seu corpo - e penetrar em sua vida cotidiana.

\section{O PODER DISCIPLINAR DO DISCURSO}

A escola é, depois da família (mas muitas vezes antes desta), a instituição de sequestro pela qual todos passam (ou deveriam passar) o maior tempo de suas vidas, no período da infância e da juventude. Na medida em que a permanência na escola é diária e se estende ao longo de vários anos, os efeitos desse processo disciplinar de subjetivação são notáveis (VEIGA-NETO, 2005, p. 70).

Por muitos anos, como forma de manter a disciplina e formar "bons cidadãos", a escola lançou mão de castigos físicos em sua rotina. Com a aprovação da sociedade e com o aval dos pais os castigos eram aplicados sobre crianças e adolescentes em nome da boa formação e incluíam os temidos "bolos" de palmatória, beliscões, reguadas, safanões e longos momentos para reflexão "cheirando" a parede ou de joelho em cima de caroços de milho.

De acordo com Douglas Ramos (2009, p. 2), tais procedimentos começaram a ser questionados na segunda metade do século XIX, quando a partir de ampla discussão entre professores, educadores, funcionários do Estado, pais de alunos e especialmente, médicos higienistas $^{8}$, os mecanismos de punição escolares foram aos poucos sendo substituídos por mecanismos 'mais civilizados"9 de controle disciplinar: o castigo moral.

Dessa forma, longe de estar ausente no ambiente escolar a punição se faz presente em uma nova roupagem que em substituição aos castigos físicos aparece de forma mais silenciosa, mas não menos eficaz (PONGRATZ, 2008, p. 41). O castigo moral não deixa marcas visíveis no corpo, mas traz outros efeitos. Esse novo processo de sujeição é retratado por Foucault em Vigiar e Punir (2009b). Nessa obra o autor mostra detalhadamente como determinadas instituições que ele chama de instituições de sequestro representadas pela prisão, escola, quartéis entre outras, passam dos castigos e violências corporais para o

\footnotetext{
${ }^{8}$ De acordo com este autor, os médicos tiveram papel preponderante na substituição dos castigos físicos porque defendiam que a escola deveria produzir "pessoas higiênicas, higienizados e higienizadores", baseando-se no saber médico como fundamento de uma "pedagogia científica" para assim traçar estratégias que trabalhassem tanto as condições ambientais da escola quanto seu domínio pedagógico. Dessa forma, a proposta defendia uma relação civilizada entre mestres, funcionários e alunos que só seria possível com a eliminação dos castigos físicos.

${ }^{9}$ Por serem mais eficientes e silenciosos.
} 
disciplinamento que cria corpos submissos, "dóceis". Vale ressaltar, no entanto, que ao se falar de corpos dóceis o autor não constrói uma relação a corpos obedientes, mas a corpos maleáveis e moldáveis que não se formam com o emprego da força.

Essa docilidade atuante no nível do corpo e dos saberes assegura a sujeição constante e produz comportamentos, formas particulares tanto de estar no mundo quanto de cada um conhecer o mundo e nele se situar (VEIGA-NETO, 2005, p. 71). Não é mais o castigo corporal que coloca cada um em seu lugar, mas os discursos circulantes ditadores da verdade.

A disciplina é a técnica específica do poder que toma os indivíduos ao mesmo tempo como objetos e como instrumentos de seu exercício. Por não se caracterizar com um poder exercido de maneira insidiosa, atua de forma modesta, desconfiada funcionando de modo calculado, sutil e permanente (FOUCAULT, 2009b, p. 142).

O poder disciplinar é exercido nas práticas cotidianas e, por este motivo, os discursos que o instituem ao longo do tempo são incorporados e naturalizados tornando-os praticamente imperceptíveis pela sua banalização. Como diz Foucault "são pequenas astúcias dotadas de um grande poder de difusão, arranjos sutis, de aparência inocente, mas profundamente suspeitos, dispositivos que obedecem a economias inconfessáveis ou que procuram coerções sem grandeza, são eles, entretanto, que levaram à mutação do regime punitivo, no limiar da época contemporânea" (FOUCAULT, 2009b, p. 134).

No curso desses princípios podemos entender as práticas escolares como dispositivos de normalização, pelo qual o sujeito aprende como e o que deve ser. Através dos discursos circulantes na sala de aula, por exemplo, processos de subjetivação vão sendo continuamente construídos de modo sutil e natural penetrando nos sujeitos, produzindo uma postura, um modo de ser e de agir, construindo o que Louro (1997, p. 61) chama de "identidade escolarizada". Através da linguagem verbal e gestual os signos são postos e a partir daí são incorporados pelos sujeitos tornando-se parte de seus corpos.

Nesse processo o sujeito acaba por ocupar as funções enunciadas pela situação discursiva. Nesse processo de assujeitamento observamos que os enunciados discursivos além de apontar para o universo pedagógico, potencialmente apontam também na direção da vida social. O discurso sob a forma de controle regulamentar que apresenta o aluno como incapaz, limitado, impossibilitado de ter voz, extrapola a realidade escolar e pode se materializar em outros ambientes (família, colegas, profissão). Dessa maneira, a construção das identificações acontece por intermédio de discursos elaborados que mantém ou alteraram as significações a respeito do que é ser aluno, ser cidadão, ser 'gente'. 
O processo disciplinador defendido por Foucault obtém sucesso através de um mecanismo de vigilância constante, exercido através do panoptismo ${ }^{10}$ que tem por princípio geral induzir sobre os vigiados um estado consciente e permanente de visibilidade que assegura o funcionamento automático do poder. Por esse modelo tem-se uma vigilância exercida de forma invisível, por isso, pouco importa se a vigilância que emana de fora (professor) seja mesmo constante, esteja sempre ali; o que importa é que aquele que é vigiado (o aluno) saiba que está sempre a mercê do olhar vigilante, ainda que não saiba exatamente quando está sendo vigiado. Como explica Foucault:

Quem está submetido a um campo de visibilidade, e sabe disso, retoma por sua conta as limitações do poder; fá-las funcionar espontaneamente sobre si mesmo; inscreve em si a relação de poder na qual ele desempenha simultaneamente os dois papéis; torna-se o princípio de sua própria sujeição. Em consequência disso mesmo, o poder externo, por seu lado, pode-se aliviar de seus fardos físicos; tende ao incorpóreo; e quanto mais se aproxima desse limite, mais esses efeitos são constantes, profundos, adquiridos em caráter definitivo e continuamente recomeçados: vitória perpétua que evita qualquer defrontamento físico e está sempre decidida por antecipação (FOUCAULT, 2009b, p. 167).

No universo escolar que descrevemos o mecanismo de vigilância se faz presente quando os alunos trazem para a mesa o discurso do antigo professor. Ele não estava mais ali, mas suas palavras ainda ecoam na cabeça dos dez alunos. Essa constante observação (que acontecia pelos olhos dos alunos) também se fez presente quando a professora solicita o trabalho final da disciplina - a elaboração de um projeto com objetivo de estudar uma determinada problemática enfrentada por eles, enquanto professores em suas respectivas escolas. Os dez alunos responderam que não eram capazes de elaborar um projeto. Em suas palavras: 'isso é muito difícil para nós'; 'não sabemos como fazer'; 'não vamos conseguir, pois essa atividade é muito complicada'; 'se dependermos dessa atividade, ficaremos reprovados novamente!'. Dentro desse mecanismo, a vigilância se mostra permanente em seus efeitos, mesmo que sua ação seja descontínua.

\footnotetext{
${ }^{10}$ O princípio do panóptico é assim explicado por Foucault: "na periferia uma construção em anel; no centro, uma torre; esta é vazada de largas janelas que se abrem sobre a face interna do anel; a construção periférica é dividida em celas, cada uma atravessando toda a espessura da construção; elas têm duas janelas, uma para o interior, correspondendo às janelas da torre; outra, que dá para o exterior, permite que a luz atravesse a cela de lado a lado. Basta então colocar um vigia na torre central, e em cada cela trancar um louco, um doente, um condenado, um operário ou um escolar. Pelo efeito da contraluz, pode-se perceber da torre, recortando-se exatamente sobre a claridade, as pequenas silhuetas cativas nas celas da periferia. Tantas jaulas, tantos pequenos teatros, em que cada ator está sozinho, perfeitamente individualizado e constantemente visível" (FOUCAULT, 2009b, p. 164).
} 


\section{RESISTÊNCIA: POSSIBILIDADES DE REVERTER A CRÔNICA DE UMA REALIDADE ANUNCIADA}

As coisas, palavras, pensamentos, teorias, práticas educacionais não existem por si sós, não estão fixadas, eternas, universais. Elas não são. Ou melhor: são à medida e somente à medida que se fazem, à medida que se revelam como um por-fazer, como um esforço de conquista e de reconquista dos percursos da educação

Sandra Mara Corazza - Uma vida de Professora

Inúmeros atos cotidianos nas escolas são expressões sutis de importantes relações de poder que se encontram naturalizadas pelo tempo e pelos atores desse cenário. Trouxemos para discussão duas situações nas quais o discurso proferido pelo professor funciona como elemento de poder, verdade e subjetivação.

No entanto, é pertinente falar que esse estado não pode ser entendido como estável e imutável. Se considerarmos que nos casos descritos temos em destaque duas (das muitas) facetas presentes no ambiente escolar, não podemos esquecer que o poder irradia em vários sentidos, perpassando todos os indivíduos. Dessa forma, não estamos engessados em uma posição de poder ou dominação. Nas palavras de Foucault:

[...] as relações de poder abrem possibilidade a uma resistência; e é porque há possibilidade de resistência (e resistência real) que o poder daquele que domina tenta se manter com tanto mais força, tanto mais astúcia quanto maior for a resistência. De modo que é mais a luta perpétua e multiforme que procuro fazer aparecer que a dominação morna e estável de um aparelho uniformizante. Em toda parte, se está em luta [...] e a cada instante se vai da rebelião à dominação, da dominação à rebelião (FOUCAULT, 2003, p. 232).

Nesse sentido a resistência pode ser entendida como toda e qualquer (re)ação de contrapoder ou contraconduta. Resistir a uma ação de poder significa problematizar tal ação, valendo-se para isso, também de poder (VEIGA-NETO, 2008, p. 22).

Como somos fruto de um processo de formação no qual a passividade e a resignação deixaram marcas profundas, ainda somos levados a ver (e a crer) que as situações como as que narramos nesse artigo são naturais, fazem parte da escola. Romper ou até mesmo questionar esses discursos não são movimentos fáceis, pois esse deslocamento requer a negação da autoridade associada à imagem do professor. Significa negar heranças e constituise em um processo de insubordinação às regras que são ditadas por esta autoridade escolar a muitos e muitos anos (FAISTEL, 2006, p. 89).

Um passo nessa direção é começar nos perguntando: o que estamos fazendo em nossas salas de aula? Quais discursos estamos veiculando como professores? Que tipo de sujeitos 
estamos ajudando a produzir? Além disso, é necessário estarmos em estado de alerta constante para que sejamos capazes de ver, ouvir e sentir as múltiplas formas de constituição dos sujeitos dentro do cotidiano escolar. Nas palavras de Louro (1997): “o olhar precisa esquadrinhar as paredes, percorrer os corredores e salas, deter-se nas pessoas, em seus gestos. É preciso perceber os sons, as falas, o que dizem nossos professores? É preciso desnaturalizar essas falas, é preciso colocá-las sob suspeita”. Como diz Corazza (2005):

É preciso desaprender o aprendido para poder ser partícipe da força de transformação, transfiguração, procriação e criação da educação. Ser educador não é só acumular, guardar, conservar, usar, mas também abandonar, largar, gastar e, neste gasto, readquirir, retomar, para poder se revitalizar (CORAZZA, 2005, p. 13).

É preciso ver os discursos circulantes na escola (e em tantas outras instituições) como algo que pode ser imobilizado, interceptado, subvertido. Essa postura vigilante não elimina as relações de poder (isso é impossível!), mas desestabiliza e problematiza o que consideramos como "natural" e nesse sentido é importante tornarmo-nos sensíveis e atentos às situações cotidianas naturalizadas, fazer o exercício de nos enxergar como fazendo parte dessas redes por onde o poder atravessa e acaba por nos constituir.

\section{CONSIDERAÇÕES FINAIS}

A aprendiz de professora pediu para que os alunos ficassem em silêncio e colocou José na frente. Falou a eles sobre a necessidade do respeito às pessoas, e olhando diretamente para a professora daquela turma falou que o sono às vezes é o sintoma da fome, de maus tratos, sinal de repúdio a uma aula desinteressante, não necessariamente sintoma de preguiça. Enquanto olhava para ela não pode deixar de notar o quanto José crescia, talvez pela primeira e única vez na vida.

Quanto aos alunos de Pedagogia, ao longo do curso a professora foi resgatando suas histórias de vida, os "causos" que traziam de seus anos de experiência como professores em comunidades que nem sequer existem no mapa. Ela procurou destacar o importante papel que cada um exercia em sua escola, sua comunidade, sua família. O ponto chave se deu quando apresentou a avaliação final realizada individualmente, um pouco a cada dia, sem que se dessem conta que eram capazes de fazê-la: um projeto escrito por eles e que estava pronto para ser executado. Após o susto geral eles puderam perceber que aquilo era apenas uma entre tantas outras possibilidades de ação. 
A professora ao agir dessa forma estava produzindo uma contraconduta, fazendo aparecer outro discurso, um discurso que se elaborou e se recriou a partir de resistências que elaborou em sua prática pedagógica a partir de dois enunciados de negação. "Não é isso que vou fazer! Não é esse tipo de discurso que quero fazer circular, não é este tipo de discurso que deve ser fomentado dentro da sala de aula". Tais enunciados participaram dos mecanismos de resistência e ao mesmo tempo da vontade de que aquela verdade fosse a "mais verdadeira" naquele momento. E acabou sendo!

\section{REFERÊNCIAS}

CORAZZA, Sandra Mara. Uma vida de Professora. Ijuí: Ed. Unijuí, 2005.

COSTA, Wanderleya Nara G.; DOMINGUES, Kátia Cristina M.; ANDRADE, Silvanio. Uma análise de práticas discursivas e não discursivas sobre o ensino de matemática em contextos indígenas. ZETETIKÉ - Cempem - FE - UNICAMP - v. 17, n. 32 - jul/dez - 2009.

DUARTE, André. Biopolítica e resistência: o legado de Michel Foucault. In: RAGO, Margareth e VEIGA-NETO, Alfredo (orgs.). Figuras de Foucault. Belo Horizonte: Autêntica, 2008.

EIZIRIK, Marisa Faermann. Michel Foucault: um pensador do presente. $2^{\text {a }}$ edição. Ijuí: Editora Unijuí, 2005.

FAISTEL, Ana Luiza Klein. A construção da identidade nos discursos de professoras. 118p. Dissertação de Mestrado. Universidade Regional do Noroeste do Estado do Rio Grande do Sul. Ijuí, Rio Grande do Sul. 2006

FOUCAUlT, Michael. A Microfísica do Poder. Rio de Janeiro: Edições Graal, 1979.

FOUCAULT, Michael. A ordem do Discurso. Rio de Janeiro: Edições Loyola, 2009a.

FOUCAULT, Michael. Em defesa da Sociedade. São Paulo: Martins Fontes, 2005

FOUCAULT, Michel. Vigiar e Punir. 36a edição. Petrópolis, RJ: Vozes, 2009b.

GADOTTI, Moacir. A escola e o professor: Paulo Freire e a paixão de ensinar. $1^{\mathrm{a}}$ edição.

São Paulo: Publisher Brasil, 2007.

LOURO, Guacira Lopes. Gênero, sexualidade e educação: uma perspectiva pósestruturalista. Petrópolis, RJ: Vozes, 1997.

MENEZES, Antônio Basílio Novaz Thomaz. Foucault e as novas tecnologias educacionais: Espaços e dispositivos de normalização na sociedade de controle. In: JUNIOR, Durval Muniz 
de Albuquerque e VEIGA-NETO, Alfredo; FILHO, Alípio de Souza (orgs.). Cartografias de Foucault. Belo Horizonte: Autêntica, 2008.

PEREIRA, Maria José de Morais. Disciplina e castigo na escola: um estudo a partir da trajetória de vida de duas professoras do Ensino Fundamental. 110p. Dissertação de Mestrado. Pontifícia Universidade Católica de Minas Gerais. 2000.

PONGRATZ, Ludwig A. Liberdade e disciplina: transformações na punição pedagógica. In: PETERS, Michael A.; BESLEY, Tina (orgs.). Por que Foucault? Novas diretrizes para a pesquisa educacional. Porto Alegre: Artmed, 2008.

RAMOS, Douglas Rossi. Práticas punitivas e de controle na escola: um estudo de caráter genealógico. In: CONGRESSO DE LEITURA DO BRASIL,17., 2009, Campinas. Anais do $17^{\circ}$ COLE, Campinas, SP,: ALB, 2009. Disponível em: http://www.alb.com.br/portal.html. Acesso em: janeiro de 2018. ISSN: 2175-0939.

VEIGA-NETO, Alfredo. Dominação, violência, poder e educação escolar em tempos de Império. In: RAGO, Margareth e VEIGA-NETO, Alfredo (orgs.). Figuras de Foucault. Belo Horizonte: Autêntica, 2008.

VEIGA-NETO, Alfredo. Foucault \& a Educação. $2^{\text {a }}$ edição. Belo Horizonte: Autêntica, 2005. 